0 TREInAmEnto Rasaboxes COMO PROPULSOR DA INVESTIGAÇÃO DA SINESTESIA VOCAL DO ATOR

Resumo

O treinamento do Rasaboxes, criado por Richard Schechner a partir do Teatro Clássico Indiano, surge enquanto um possível propulsor de uma investigação mais aprofundada e complexa das potencialidades sinestésicas da voz e da palavra falada do ator. A questão principal que será aqui levantada traz a indagação de como o treinamento do Rasaboxes se encaixa no escopo da vocalidade do ator e o auxilia na busca da sinestesia presente em sua voz?

Palavras-chave:

Rasaboxes. Voz. Sinestesia. 


\title{
O TREINAMENTO RASABOXES COMO PROPULSOR DA INVESTIGAÇÃO DA SINESTESIA VOCAL DO ATOR
}

\author{
Kevin Cesar de Mattos Balieiro (Unicamp) \\ Gina María Monge Aquilar (Unicamp)
}

Kevin Cesar de Mattos Balieiro - Mestrando no Programa de Pós-graduação em Artes da Cena.

kevin_fox283@hotmail.com

Gina María Monge Aguilar - Doutora e Mestre em Artes Cênicas: Pedagogia do Teatro, pela Universidade de São Paulo USP. Professora no Departamento de Artes Cênicas da Unicamp. ginamonge@gmail.com
Em consonância ao foco no trabalho vocal do ator, o treinamento denominado Rasaboxes, criado pelo diretor, professor e performer americano Richard Schechner a partir do Teatro Clássico Indiano, em consonância ao Atletismo Afetivo, conceito cunhado pelo teatrólogo, diretor, ator e poeta francês Antonin Artaud, e aos princípios da Neurociência, surge como uma frutífera fonte de investigação e experimentação da potência sinestésica da vocalidade em cena. Entretanto, antes de adentrarmos nesta principal questão, é preciso contextualizar tanto o Rasaboxes quanto o conceito do Atletismo Afetivo, e também a sinestesia.

Michele Minnick e Paula Cole, ex-alunas de Schechner, apontam o princípio do treinamento do Rasaboxes:

O mais básico princípio do Rasaboxes é que qualquer ideia que o ator quer comunicar tem que estar de alguma maneira corporificada, recebida por e expressada em ou através do corpo, mesmo que seja somente no nível da respiração. [...] enquanto a emoção perpassa o corpo, ela modela o comportamento de acordo com suas demandas e, em troca, reabastece a imaginação e inicia impulsos físicos (COLE; MINNICK, 2002, p. 2). 
O treinamento do Rasaboxes se configura na forma de um tabuleiro demarcado no chão do espaço em que será realizado, com dimensões de dez metros de largura por dez de comprimento, formando um grande quadrado que deve conter em seu interior nove outros quadrados menores. Cada um destes quadrados é chamado de rasa, palavra em sânscrito que significa deleite, suco, essência ou sabor. Cada rasa delimita uma emoção (ou deleite, essência, etc.) e suas mais infinitas variações, sendo elas: Sringara (amor), Hasya (riso), Adbhuta (surpresa), Karuna (tristeza), Vira (coragem), Raudra (raiva), Bhayanaka (medo), Bibhasta (nojo) e Shanta (paz). O treinamento se inicia com a aproximação dos atores ao tabuleiro; em seguida, cada um deve adentrar a uma das rasas e iniciar a prática do exercício, primeiramente adotando posições imóveis que denotem, com a máxima intensidade do corpo, cada uma das emoções. Em sequência, o estático dá lugar à respiração, depois ao movimento, seguido do som e partindo para a introdução de variados elementos como textos, objetos, música e iluminação, criando um jogo complexo de exteriorização das mais variadas sensações e emoções pelo corpo e pela voz do ator.

Júlia Sarmento, atriz, palhaça e Mestre pela Universidade Federal do Ceará, denota as duas únicas regras do treinamento e, de forma sucinta, o percurso que ele percorre, como já apontado acima:

Cabe aos atores [...] construir com o corpo, pelo espaço demarcado, tais "sabores", com a máxima intensidade, mudando de rasa à medida que se deslocam pelo tabuleiro. As únicas regras são as de explorar as rasas com o corpo todo e mudar de um quadrado para outro mudando também a rasa de modo imediato. [...] A respiração vem em seguida, passando aos gestos estáticos e dinâmicos até as improvisações livres em duplas ou trios. Trabalham-se ainda os registros vocais de cada rasa e a inserção de objetos, música e textos a partir das texturas conquistadas ao longo do processo (SARMENTO, 2013, p. 3).

Vê-se, então, que o treinamento do Rasaboxes é voltado principalmente ao corpo e à externalização das emoções, visando o exterior (físico) em contraponto ao interior (psicológico). Embora um impulsione o outro, o exterior é mais enfatizado do que o interior, sendo os impulsos interiores catapultas para a exteriorização física das emoções. Sarmento (2013) reforça: "A exterioridade alimentará a interioridade não para tornar a experiência mais profunda, mas para convertê-la mais e mais em exterioridade" (SARMENTO, 2013, p. 4). O Rasaboxes também se fundamenta no jogo, tanto do ator para consigo mesmo quanto dele para com o outro (nas improvisações em duplas ou trios, com textos, objetos, etc.); e a intensidade do treinamento deve ser sempre máxima, ou seja, $o$ ator deve dar tudo de si quando se encontra dentro do tabuleiro. A emoção, assim, é tirada do contexto "mente" e passa a ser enxergada enquanto transpositora à realidade física - não se "sente" a emoção, se "mostra" a emoção: tudo o que é sentido deve ser mostrado ao público. $\mathrm{O}$ ator, no treinamento do Rasaboxes, engaja o complexo emoção-corpo-voz-imaginação-personagem, e é partir deste "todo" que podem surgir cenas e performances, personagens e textos, vozes e corpos diferenciados. Citando novamente Cole e Minnick,

Quando alguém fica completamente conectado energeticamente com a emoção, está trabalhando com ela vindo do exterior, até que seja o interior e novamente o exterior. Ao invés de focar no interior ou no exterior, os Rasaboxes encorajam uma aproximação holística ao relacionamento entre os aspectos interiores e exteriores da arte do ator, gerando um diálogo frutífero entre mente e corpo (COLE; MINNICK, 2002, p. 2).

Desse modo, os autores mencionados anteriormente descrevem a inserção do som e da voz a partir da respiração no treinamento das rasas:

[...] engajando a respiração, sentindo como ela pode encher e animar a forma do corpo. Então, a fisicalização da rasa dá forma à voz. [...] As primeiras poses/sons frequentemente têm a qualidade de clichês sociais - do "já conhecido", que encaixam nas rasas como casualmente subentendido. Grandes risadas para hasya, punhos cerrados para raudra, choro para karuna e assim por diante. 
[...] Mais cedo ou mais tarde, o estereótipo/ arquétipo social vai ser ampliado por gestos e sons que serão mais íntimos, pessoais, peculiares, inesperados (COLE; MINNICK, 2002, p. 12)

Nota-se que a prática no Rasasboxes incita o ator a percorrer novos caminhos, tanto com o corpo quanto com a voz e com o som, ou seja, com seu corpo-voz (afinal, um não pode ser desvencilhado do outro, uma vez que são o mesmo). Ele incita-o a escapar dos estereótipos e do comumente conhecido e a adentrar a registros mais pessoais e peculiares, diferenciados. Esta é a proposição para a utilização da voz do ator: vozes "extra-cotidianas", "extra-ordinárias", que percorrem lugares desconhecidos, fugindo do já conhecido, e adquirindo o poder de chocar, encantar e purgar o público que o assiste. Entra em cena, então, a sinestesia.

A sinestesia, cientificamente falando, é o fenômeno no qual uma sensação de uma específica ordem sensorial é disparada por um estímulo de uma ordem sensorial diferente, isto é, uma imagem que leva uma pessoa a sentir um cheiro, ou um som que a leva à visualização de uma imagem. A sinestesia também pode ser a ocorrência de múltiplas sensações simultâneas, todas de ordens sensoriais diferentes: audição, olfato, visão, paladar e tato se confundindo a partir de um estímulo sensorial específico. Do ponto de vista da ciência, a sinestesia nada tem de subjetiva, sendo considerada um fenômeno físico delimitado a estes "sintomas". As pessoas que demonstraram tal "habilidade" no decorrer da história foram chamadas de "sinestetas", sendo colocadas em um "pedestal” da percepção humana, de acordo com Sérgio Basbaum, Doutor em Comunicação e Semiótica, especializado em ciências cognitivas, em um trabalho realizado em 2003. No entanto, há opiniões que vão na contramão do postulado científico acerca da sinestesia, afirmando que ela é um estado de percepção inerente a todos os seres humanos e que pode ser despertado a qualquer momento por acontecimentos, vivências e, principalmente, experiências artísticas.

É desta maneira que a sinestesia vem a ser entendida aqui: um estado de percepção pertencente a todos os seres humanos, passível de ser despertado em qualquer um, no qual sensações físicas das mais diversas ordens, imagens, memórias, arrepios, sonhos, lágrimas, sorrisos, sons, cheiros, enfim, infinitas sensações de todos os tipos, de todas as ordens, borbulham no corpo da pessoa que o vivencia, corpo este que entra em profusão, intercruzando muito mais do que apenas os cinco sentidos humanos conhecidos.

A sinestesia, então, é compreendida como um estado passível de ser disparado em um indivíduo a partir de diversas experiências, entre elas, a vivência artística, como o teatro. E não seria este o estado almejado por todos os atores, diretores e atuantes da área a ser despertado no público e em si mesmos através da obra cênica apresentada? Um estado diferenciado que leva tanto o espectador como o próprio ator em cena a um lugar único de percepção e sensação. Não é este o poder de "encantamento", como diz Artaud (1999), que o teatro deve ter? Poderia a voz do ator ser a propiciadora deste fenômeno tão único e arrebatador? E, por fim, como o treinamento do Rasaboxes poderia auxiliar na descoberta e na externalização da potência sinestésica que jaz no trabalho do ator, e especificamente, em sua voz e em sua palavra falada?

Aproveitando a ponte criada com Artaud, este cunhou o conceito de Atletismo Afetivo em sua obra O Teatro e seu Duplo (1999, pp. 151-160), da qual Schechner se utilizou para idealizar o treinamento do Rasaboxes. Sarmento (2013) explica:

A partir da ideia de que o homem possui uma fisiologia de afetos que seria análoga ao corpo orgânico, Artaud evoca um ator que seja capaz de acessar e manipular tal fisiologia de paixões. Na mesma medida em que um atleta conhece e treina seu corpo orgânico para atingir melhores resultados, o ator também se dedicaria a um treino, porém de seu corpo afetivo, para manipular paixões e alcançar intensidades capazes de atingir e purgar as plateias (SARMENTO, 2013, p. 2).

Ou seja, para Artaud (1999), o corpo de um atleta é análogo ao corpo do ator: enquanto 
um treina seu corpo físico para atingir melhores resultados na prática de seu esporte, o outro treina seu corpo afetivo (seus afetos, emoções, paixões, sensações, subjetividades), também para atingir melhores resultados na prática de sua linguagem artística. Artaud (1999) contextualiza tanto o "corpo orgânico" quanto o "corpo afetivo", sendo o corpo orgânico o seu físico e o corpo afetivo, os seus afetos. Pode-se traçar um paralelo entre estas duas ideias ligando-as à voz: é possível pensar tanto na "voz orgânica" quanto na "voz afetiva" do ator. No entanto, neste caso, o ator e o atleta fundem-se em um só, pois o ator precisa treinar tanto sua voz orgânica quanto sua voz afetiva, não sendo possível a existência de uma sem a outra.

Jerzy Grotowski, diretor teatral e teórico polaco, em suas obras $O$ Teatro Laboratório de Jerzy Grotowski 1959-1969 e Em Busca de um Teatro Pobre, traz sistematizações metodológicas de vários exercícios direcionados à voz, uma vez que seu teatro era inteiramente voltado ao trabalho do ator, e sendo a voz grande parte deste trabalho, ela ocupa um lugar importante - e extenso - em seus livros. Neles, Grotowski coloca o aparelho fonatório - o orgânico - da voz como prioridade, para que o ator alcance uma qualidade vocal sensível e afetiva satisfatória - $\mathrm{o}$ afetivo. Deve-se treinar e cuidar da laringe, faringe, pregas vocais, simultaneamente à exploração das cavidades faciais, deslocamento de oxigênio e caixas de ressonância, para que se obtenha total controle e conhecimento da voz orgânica, para então passar à investigação da potência poética que existe em seu lado afetivo. Assim, torna-se mais claro o que é a voz orgânica e a voz afetiva, separando-as e delimitando o que cada uma representa ao ator: a voz orgânica enquanto o físico, fisiológico, o aparato vocal; a voz afetiva enquanto as possibilidades de sensação que podem ser emanadas dela e de suas palavras a partir das subjetividades do ator. Traça-se, aqui, um paralelo entre o conceito de Atletismo Afetivo de Artaud (1999) e a voz, trazendo Grotowski enquanto embasador desta ideia, visto que a voz orgânica e a voz afetiva podem ser pensadas pelo ator em conjunto na busca da potência sinestésica da voz. Mas como os Rasaboxes se encaixam neste lugar tão espe- cífico voltado à voz e auxiliam o ator no treinamento tanto de sua voz orgânica quanto de sua voz afetiva, em consonância ao seu corpo, em busca da sinestesia?

Tendo, então, contextualizado o Rasaboxes, o Atletismo Afetivo e a sinestesia, parte-se para a questão central do presente artigo: a voz. $\mathrm{O}$ treinamento do Rasaboxes, segundo Cole e Minnick, pode ser extremamente frutífero nesta busca pela potência sinestésica a partir da exploração vocal, tanto técnica quanto sensivelmente. Ao introduzir aos atores no treinamento das rasas o texto e a palavra falada, as dinâmicas (antes, somente corporais) tornam-se sonoras, forçando os atores a treinarem, em conjunto ao corpo, suas vozes, tanto orgânicas quanto afetivas, ao lançarem textos dos mais variados (dramáticos, poemas, etc.) pelo espaço:

[...] expandimos as possibilidades de relação através da incorporação de textos memorizados (cena, monólogo, ou poema). [...] As palavras são usadas como textos abertos, focando a exploração de como cada rasa informa esse texto diferentemente, ao invés de focar em personagens, circunstâncias dadas, ou outros elementos do texto da peça (COLE; MINNICK, 2002, p. 15).

Evocando a pesquisadora de voz e fonoaudióloga Lucia Helena Gayotto, é possível enxergar a importância do trabalho com o texto - com a palavra - na investigação e experimentação vocais do ator. Gayotto (1997) afirma que

[...] o texto é uma pele, um tecido a cobrir a carne, os ossos, o sangue, as vísceras de uma humanidade inaudita, oculta, impronunciável, profunda, milenar, que cada palavra exige para ser manifesta. A compreensão dessa dimensão da fala é que faz com que tenhamos a emissão vocal cênica como algo que não se pode dar numa enunciação impensada, como mera tagarelice, ou fala decorada. $\mathrm{O}$ ator se apropriará daquilo que diz, se dando como terra para as palavras [...] (GAYOTTO, 1997, p. 33).

O trabalho com o texto pode ser pensado enquanto sua grande junção com as sonoridades e com as palavras. Mas como pode o texto se tornar um propulsor da potência sinestésica 
vocal? Pensa-se que no Rasaboxes, o texto passa a ser enxergado enquanto um grande desenho sonoro - ele deixa de ser somente uma grande massa de combinações entre palavras e frases, ganhando som e voz através das mais variadas emoções e sensações: como fazer vibrar uma frase de maneira a transformar o sentido que ela transmite através da raiva? Como pulsar uma palavra na rasa do amor, ou do riso, ou da tristeza? O trabalho da voz com a palavra no Rasaboxes se configura, então, como uma grande rede de investigação vocal em busca de transformações sinestésicas a partir da exploração de cada rasa e emoção. As pausas, os silêncios, as rubricas, os parágrafos, solilóquios, hesitações, exclamações e tudo o que existe dentro de um texto pode adquirir uma proporção muito maior do que normalmente teria quando este é trabalhado pelo ator de maneira a buscar a sinestesia, impulsionado pelo treinamento do Rasaboxes.

Assim sendo, o momento em que os atores presentes no grande quadrado das rasas introduzem, a partir da respiração, o som, é o início do trabalho com a voz o qual deve ser visada a sinestesia, visto que ela se configura como estado corpóreo e sensorial a ser disparado tanto nos próprios atores quanto no público que os assiste, arrebatando a todos o lugar de percepção e sensação diferenciados, únicos e transcendentais. Introduz-se, então, o trabalho com a palavra falada - com o texto - a partir de escritos dramáticos, poemas ou outros, ampliando e aprofundando a investigação vocal a partir das rasas e das possibilidades que o próprio texto oferece ao ator. Como Gayotto (1997) afirma, o texto é de essencial importância ao trabalho vocal do ator, pois a sua dimensão poética exige que "tenhamos a emissão vocal cênica como algo que não se pode dar numa enunciação impensada, como mera tagarelice, ou fala decorada" (p. 33). Segundo ela, o texto força o ator a buscar uma emissão vocal "digna" ao escrito que profere, visto que todo texto surge de lugares extremamente pessoais e íntimos contidos tanto no autor quanto nos seres humanos e na humanidade como um todo. Assim, o trabalho com o texto no Rasaboxes se mostra essencial e potente na experimentação vocal do ator.

O escritor franco-suíço Valére Novari- na reforça a importância da palavra falada enquanto potência da vocalidade do ator: segundo Novarina (2003), a linguagem e suas palavras são forças que delimitam a existência de tudo, golpeando os ouvidos ao serem proferidas - são forças vivas. As palavras podem pintar, desenhar, agredir e invocar sensações naquele que as ouve e naquele que as diz, revelando-se muito mais do que utilitárias ferramentas de comunicação. A sinestesia é pensada como a força arrebatadora que Novarina (2003) agrega à palavra falada e à voz no teatro, e ao estado de percepção diferenciado que estas podem despertar em uma pessoa - em um ator, em um espectador. A força sinestésica da palavra que pula para fora da boca do ator como um "caroço a ser quebrado para que sua respiração seja liberada” (p. 17), através da voz, é pensada, neste artigo, como propulsora de experiências sensoriais únicas, dignas de serem almejadas pelos atores e pela arte do teatro.

O treinamento do Rasaboxes, apesar de ser focado muito mais no corpo do que na voz em si, pode ser enxergado enquanto um propiciador da sinestesia vocal, da força da palavra que Novarina (2003) e Gayotto (1997) situam, da investigação e da experimentação da voz e da palavra que podem ser catapultas do acontecimento sinestésico na cena. Para contextualizar e embasar este pensamento acerca do Rasaboxes e da voz, registro, aqui, um experimento realizado por mim durante a aula de uma das disciplinas cursadas no Programa de Pós-graduação em Artes da Cena da Universidade Estadual de Campinas. Propôs-se o seguinte exercício aos outros colegas de sala durante o período de uma hora: eles passariam pelo treinamento do Rasaboxes, percorrendo o caminho exato descrito por Sarmento (2003), ou seja, iniciariam o exercício construindo poses estáticas delimitando com o corpo, em intensidade máxima, as emoções de cada rasa em que estivessem inseridos. Em seguida, passariam ao movimento e, sequencialmente, ao som. Foi avisado que o foco principal deveria recair no som e nas palavras faladas do texto que eu viria a lançar a eles durante a realização do exercício - não somente no corpo, mas principalmente na voz. Após experimentar o Rasaboxes por um tempo, um 
por um eles sairiam do quadrado e se colocariam diante de uma mesa com um objeto sobre ela. Todos deveriam escolher mentalmente algumas palavras do texto praticado nas rasas e, conforme eu fosse manipulando o objeto no ar - brincando com ele de diferentes formas -, eles iriam manuseando suas vozes à medida que fossem dizendo as palavras, contaminados pela experiência vocal investigada no Rasaboxes. Por último, um por vez, eles se sentariam em uma cadeira alocada no espaço e diriam o texto praticado no Rasaboxes e com o objeto sobre a mesa três vezes seguidas, explorando ao máximo as diferentes possibilidades de dizer o texto vocalmente, procurando destoar ao máximo um modo de dizer do outro. O exercício, então, teve início.

Inicialmente, ao lançar o texto (foi escolhida uma frase de um texto do dramaturgo irlandês Samuel Beckett "tentar de novo, falhar de novo, falhar melhor" devido às suas inúmeras possibilidades de interpretação e sonorização a partir de diversas emoções que se encaixam à tais palavras), após um tempo de treinamento corporal no Rasaboxes, os atores tiveram certa dificuldade em explorar ao máximo as vocalidades possíveis a partir de cada emoção que cada rasa oferecia, confundindo-se um pouco entre focar no corpo ou focar na voz. Entretanto, com o passar do tempo, em questão de minutos, corpo e voz tornaram-se um só, assim como a sua intensidade de execução do exercício: as diferentes vozes ecoando pela sala foram gradualmente se tornando corpóreas, mais fortes, mais concretas e extremamente peculiares. Os atores experimentando a rasa da raiva, por exemplo, exploraram as palavras faladas com vozes entre os dentes, quase inaudíveis, ao invés do clichê que seriam gritos de ódio e explosões de raiva. Aqueles que se encontravam na rasa do riso exploraram vozes próximas ao choro, explorando o riso descontrolado que leva às lágrimas e como seria a voz neste estado, em vez de escolherem o caminho mais óbvio, que seria uma voz risonha, repleta de gargalhadas. E assim aconteceu por todas as rasas: os atores, inconscientemente, buscaram a sinestesia presente na voz, que surge a partir das maneiras mais estranhas possíveis de se utilizá-la em cena. $\mathrm{O}$
Rasaboxes se mostrou extremamente eficiente na exploração vocal dos atores, uma vez que cada emoção proporciona diversas possibilidades de explorações, tanto corpóreas quanto vocais. Conforme eles trocavam de rasa, trocando a emoção, suas vozes se transformavam drasticamente, em conjunto a seus corpos. Os efeitos naqueles que estavam do lado de fora assistindo (eu e o professor) foram visíveis tanto em nossos corpos quanto em nossos rostos: expressões de estranhamento e de curiosidade, sorrisos de maravilhamento, corpos tensionados, relaxados, leves suspiros e sons quase inaudíveis que saíam de nossas bocas instigados pelos atores dentro do Rasaboxes, levando-nos a querer participar, a falar com eles. Neste momento, então, os atores e nós, os espectadores, se fundiram em um só. Estávamos dentro do Rasaboxes com eles, apesar de estarmos fora. A barreira entre plateia e palco dissolveu-se, tamanha foi a intensidade da prática que tomou lugar naquele espaço. As vozes dos atores nos infectaram de maneira a nos levar a um lugar de transcendência, beirando o acontecimento sinestésico.

Em seguida, na segunda etapa do exercício proposto, os atores foram se familiarizando mais com o trabalho vocal e com a exploração das possibilidades sonoras com a palavra, conforme eu manipulava o objeto e eles brincavam com suas vozes. E foi, então, na última etapa que o acontecimento se instaurou: ao sentarem na cadeira, um por um, e dizerem o texto três vezes seguidas, explorando as mais variadas possibilidades de emissão daquelas palavras, eles mesmos se surpreenderam com aquilo que saiu de suas bocas. Qualidades sonoras palpáveis, peculiares, diferenciadas, permeadas visível e auditivamente pelas emoções experienciadas no Rasaboxes. O texto de Beckett, que inicialmente, num primeiro olhar, conota uma sensação de tristeza e desesperança, transformou-se em alegria, raiva, sensualidade, paz, heroísmo e diversas outras emoções trazidas do Rasaboxes, o que transformou completamente o próprio texto e seu sentido comumente conhecido. Assim, a exploração vocal propiciada pelas rasas teve $o$ poder não somente de transformar as vozes dos atores, mas de transformar o próprio texto e o sentido que ele transmite. Como afirmam Cole 
e Minnick (2002), “assim como as rasas podem servir como um espaço para a interpretação de textos, elas também podem gerar estímulos para a criação de novos textos [...]" (p. 22). Um novo texto surgiu de um já existente; o texto que saía da boca dos atores não era aquele de Beckett e, ao mesmo tempo, era. Todos na sala tiveram um vislumbre do que é a sinestesia: a profusão de sensações, sentidos, emoções, estados corporais, memórias e imagens; uma grande mistura de tudo ao mesmo tempo, uma exploração do desconhecido tanto pela voz quanto pelo corpo, tanto pelo orgânico quanto pelo afetivo, causadora de um arrebatamento, estranhamento sensível e possível de transportar todos aqueles que estiverem presentes no momento deste singular acontecimento a um lugar outro, um lugar extraordinário de percepção, de uma boa confusão mental e sensorial.

Assim sendo, em conclusão, o treinamento Rasaboxes se mostrou extremamente potente e um frutífero exercício no que diz respeito à investigação e experimentação vocais do ator em busca da sinestesia, tanto através do exercitamento de sua voz e corpo fisiológicos quanto de seus afetivos, uma vez que ele propicia diversas emoções e sensações a serem exploradas em intensidade máxima pelo ator e exteriorizadas ao público. Devido a esta regra específica, estabelecida por Schechner, tudo o que é sentido e desenvolvido pelo ator durante a prática nas rasas, é externalizado e mostrado ao espectador, não deixando espaço para que ele guarde para si nenhuma das experiências obtidas em seu corpo e em sua voz: tudo é exposto, tudo é exteriorizado, tudo que vem do interior é jogado ao exterior, proporcionando assim uma experiência única tanto para aquele que pratica (o ator) quando para aquele que assiste (o espectador). 


\section{REFERÊNCIAS}

ARTAUD, Antonin. O Teatro e seu Duplo. São Paulo: Martins Fontes, 1999.

BASBAUM, Sérgio. Sinestesia e percepção digital: Teccogs. 6. ed. São Paulo: 2012. Disponível em: <http://www.pucsp.br/pos/tidd/teccogs/artigos/2012/ edicao_6/9-sinestesia_e_percepcao_digital-sergio_basbaum.pdf $>$. Acesso: $17 \mathrm{de}$ agosto de 2017.

GAYOTTO, Lucia Helena. Voz, partitura da ação. São Paulo: Summus, 1997.

GROTOWSKI, Jerzy. Em busca de um teatro pobre. 4. ed. Tradução de Aldomar Conrado. Rio de Janeiro: Civilização Brasileira, 1992.

GROTOWSKI, Jerzy; FLASZEN, Ludwik (curad.); BARBA, Eugenio (text.). O Teatro Laboratório de Jerzy Grotowski 1959-1969. São Paulo: Fondazione Pontedera Teatro/Perspectiva/SESC-SP, 2007.

NOVARINA, Valère. Diante da palavra. Tradução de Angela Leite Lopes. Rio de Janeiro: 7letras, 2003.

COLE, Paula Murray; MINNICK, Michele. $\mathbf{O}$ ator como atleta das emoções: o rasaboxes. Artigo traduzido por de Ana Bevilaqua, Márcia Moraes e Michele Minnick. Disponível em: <www.rasaboxes.org>. Acesso em: 17 de agosto de 2017.

SARMENTO, Júlia. Rasaboxes e o problema do centro. 2013. 6 f. Dissertação (Mestrado) - Universidade Federal do Ceará. São Paulo: 2013. Disponível em: $<$ http://www.portalabrace.org/viireuniao/estperformance/SARMENTO_Julia. pdf>. Acesso em: 17 de agosto de 2017. 


\begin{abstract}
The Rasaboxes' training, created by Richard Schechner from the Classic Indian Theatre, emerges as a possible propellant of a deeper and more complex investigation and experimentation of the sensitive and synesthetics potentialities of the actor's voice and of their spoken word. The main issue which will be raised here brings forward the inquiry of "how does the Rosaboxes training fit into the scope of the actor's vocalitie?".
\end{abstract}

\title{
Keywords
}

Rasaboxes. Voice. Synesthesia. 